\title{
Versatility of Buccal Pad of Fat in the Reconstruction of Oral and Maxillofacial Defects - A Review
}

\author{
Jimson Samson¹, Pandiyarajan Pandurangan², Anandh Balasubramanian , Jones Jayabalan ${ }^{4}$ \\ 1,2, 3, 4 Department of Oral \& Maxillofacial Surgery, Tagore Dental College \& Hospital, \\ Rathinamangalam, Tamil Nadu, India.
}

\section{ABSTRACT}

\section{BACKGROUND}

The maxillofacial region has several congenital and acquired defects. Because of its abundant blood supply and proximity to different intraoral abnormalities, the buccal fat pad flap (BFP) is a simple and reliable flap that can be used to repair a variety of these abnormalities. BFP has remarkable qualities as a scaffold and autogenous dressing in the healing of intraoral defects after excision of oral cavity intraoral lesions. Filling and allowing slippage of fascial spaces between muscles of facial expression, advancement of intermuscular motion, isolating mastication muscles from one another, counteracting negative pressure during suction in the newborn, protection and cushioning of neurovascular bundles from injuries are among the functions of BFP. It also has a dense venous network that facilitates exoendocranial blood flow via the pterygoid plexus. For many years, the BFP was considered a surgical annoyance due to its incidental encounter during various surgeries in the pterygomaxillary space or following injuries to the craniofacial region. However, various clinical applications of BFP have been introduced in recent years. We looked at BFP and its anatomical foundation, surgical procedures, and clinical applications in this review article. The surgical method is easy and effective in a wide range of clinical situations, including oroantral fistula closure, congenital defect rectification, Osteoradionecrosis treatment, and reconstruction of tumor or cyst defect. Thus BFP is a dependable flap that may be used in a variety of therapeutic conditions.

\section{KEY WORDS}

Buccal Fat Pad Flap; Oral Mucosa; Reconstruction; Defect.
Corresponding Author: Dr. Jimson Samson, Professor \& Head of the Department, Tagore Dental College \& Hospital, Rathinamangalam, Melakottaiyur (po), Chennai - 600127, Tamil Nadu, India. E-mail:maxfacs@tagoredch.in

DOI: $10.14260 /$ jemds/2021/696

How to Cite This Article:

Samson J, Pandurangan P, Balasubramanian $A$, et al. Versatility of buccal pad of fat in the reconstruction of oral and maxillofacial defects - a review. J Evolution Med Dent Sci 2021;10(38):34413445, DOI: 10.14260/jemds/2021/696

Submission 02-07-2021,

Peer Review 25-08-2021,

Acceptance 01-09-2021,

Published 20-09-2021.

Copyright (C) 2021 Jimson Samson et al. This is an open access article distributed under Creative Commons Attribution License [Attribution 4.0 International (CC BY 4.0)] 


\section{BACKGROUND}

The buccal fat pad is a lump of specialized fatty tissue in the masticatory region that is distinct from subcutaneous fat and is located anterior to the masseter muscle and deep to the buccinator muscle. It is made up of a main part and four extensions that separate the masticatory muscles from one another as well as from bony structures like the zygomatic arch and the mandible's ramus. ${ }^{1}$ Stem cells derived from BFP has osteogenic capacity, hence BFP acts as a valuable cell source for bone tissue formation. ${ }^{2}$ Soft tissue covering is necessary for successful wound healing. When compared to other wound locations, intraoral wounds have certain distinct characteristics. There is no fatty layer in the gingiva, and the soft tissue overlying the alveolar bone is quite thin. As a result, vascularized skin grafts are excessively bulky in most cases, and their colour does not match with that of the oral mucosa, so BFP is a better option than skin transplant in reconstruction of oral and maxillofacial defects. ${ }^{3}$

Various disorders or diseases might cause an intraoral soft tissue defect. Cleft palate and lip are congenital deformities that occur in conjunction with adequate bone abnormalities. ${ }^{4}$ In cases of severe sinus pneumatization, an oroantral fistula is frequently seen after tooth extraction. ${ }^{5}$ Tumors, cysts, soft palate elongation, vocal cord augmentation, temporomandibular joint (TMJ) reconstruction, postincisional fibrotomy covering in oral submucous fibrosis, and root coverage are some of the other issues that can be treated with BFP. 6,7

\section{History}

In 1727, Lorenz Heister was the first to discover the buccal fat pad. ${ }^{6}$ He believed it to be glandular in nature, and Bichat was the first to describe it as a fatty tissue in 1801.7 Scammon was the first to characterize the anatomy of the BFP, followed by Goughran. For long years, the BFP was considered as a surgical inconvenience because of its inadvertent contact in different surgical technique defects in the craniofacial region and pterygomaxillary space.

After Egyedi (1977) defined BFP as a versatile pedicled graft for covering post-surgical maxillary defects and for closing oronasal and oroantral communications, its use has risen. ${ }^{8}$ The use of buccal pad fat as a free graft to close oral deformities was documented by Neder. ${ }^{9}$ In their study, Tideman et al. (1986) documented its anatomy, vascular supply, and operating method.10

\section{Anatomy of Buccal Pad of Fat}

BFP is compact lobulated masses with a central body and four extensions which are buccal, pterygopalatine, pterygoid and temporal extensions. The main body is enclosed by a thin capsule, and is located deep to the posterior aspect of maxilla and upper most fibers of the buccinator muscle. The buccal extension is a part of the contour of the cheek that is located superficial to the cheek. Total weight of buccal extension and main body is accounted to be 55 to $70 \%$. BFP tissue extends from the inferior orbital fissure to the pterygopalatine fossa in the pterygopalatine extension. The pterygoid extension is a deep extension in the pterygomandibular region that contains the mandibular neurovascular bundle and lingual nerve.
The temporal part is divided into two extensions, superficial and deep. The superficial component of the BFP's temporal process is visible between the deep temporal fascia, temporalis muscle, and tendon. The anterior end wraps over the temporalis muscle's anterior rim and extends to the deep section. Between the frontal process of the zygoma and the lateral orbital wall, the deep portion of the temporal process turns inward into the infratemporal region. Each process has its own capsule, which is held in place by ligaments that connects it to the surrounding structure. The pterygoid and temporal extension are variable in size. They are usually smaller than the body and the buccal extension.11,12 The superficial temporal fat pad is a unique fat pad with a distinct appearance, physical separation, and vascular supply from the BFP. It is located between two layers of deep temporal fascia. ${ }^{13}$

The parotid duct runs anterior (superficially) to the buccal branches of the facial nerve, and it enters into buccinator muscles mostly on lateral aspect of the fatty tissue, entering the oral cavity opposite the second molar. The BFP's anterior extent is marked by the facial vessels, which are in the same plane. The BFP receives blood from the transverse facial branches of the superficial temporal artery as well as buccal and deep temporal branches of the maxillary artery, and branches of the facial artery. ${ }^{14,15}$

\section{Healing Process of the Buccal Fat Pad}

The exposed fat surface becomes yellowish white in 3 days and then gradually changes to red in 7 days due to formation of new granulation tissue. In the second week, it transforms into firmer granulation tissue, and three weeks later, it gets completely epithelialized. ${ }^{16}$

\section{Surgical Technique}

Under local or general anaesthesia, an upper mucosal incision is made posterior to the zygomatic buttress, followed by a simple incision through the periosteum and fascial layer of the BFP. The yellowish-colored buccal fat is exposed by gentle blunt dissection anterior and medial to the coronoid process with fine curved artery forceps. For additional hard dissection, a second vascular clamp is necessary, one to gradually draw out the emergent part and the other to dissect the tissues from around BFP. Once the BFP is revealed, mechanical suction must be avoided. With a little coaxing, it simply by a vascular clamp, herniates into the defect and is gradually drawn out of its bed. External compression can be applied to the temporal and lateral orbital regions at this time to aid fat clearance from the temporal process. Depending on the amount of fat needed, various fat pads surgical techniques can be used as a random or pedicled flap. ${ }^{17,18,16}$

\section{Clinical Application}

Oroantral Fistula (OAF)

The communication between the maxillary sinus and the oral cavity due to the loss of typically separating soft and hard structures is a pathological condition. Orosinusal communications are common in upper molar and premolar dentoalveolar surgery, but they can also be produced by cystic disease, infections, tumors or trauma. ${ }^{19,20}$

Allogenous bone grafts, autogenous bone grafts, local and distant soft tissue flaps and synthetic materials have all been 
presented as options for OAF closure, each with its own set of benefits and drawbacks. Buccal fat pad has recently become more widely employed in the treatment of OAF and other oral abnormalities around the world. BFP is a suitable alternative for palatal fistula repair because of its ease of access, abundant blood supply, and low morbidity and failure rate, $21,22,23$

\section{Congenital Defect}

A cleft palate is a common birth defect. It's caused by the maxillary processes inadequate fusion during the developmental period. Despite the fact that several etiologies such as the environment and genetics have been proposed, the pathogenesis of congenital defects remains a subject of debate. Levi et al. pioneered the use of pedicled BFP in conjunction with the hard palatal 2 - flap and the furlow repair surgery for primary cleft palate correction, suggesting less donor site morbidity and less dissection. ${ }^{24,25}$ They theorized that an addional layer of vascularized BFP flap helps to fill and lines this open denuded area, improves vascularity in this area, and may delay or even prevent significant contracture of wound. Using this approach they hoped that, there would be reduced scar contraction and transverse maxillary development restriction which is caused by the lateral hard palatal tissue defect and buttress areas. In their study, there was no change in the child's cheeks. ${ }^{26,27}$

Many factors influence the success rate of cleft palate surgery. The bigger palatine artery and the lesser palatine artery supply blood to the primary flap for cleft palate surgery. The flap width will be narrowed if the palatal defect is large. Long, thin flaps can restrict blood flow, and vast areas of exposed rough bone surface after surgery can cause significant wound contracture. ${ }^{28,29}$ The post-operative palatal fistula in ischemic damage and wound contracture is the most common cause. BFP is especially beneficial in the treatment of secondary defects following cleft palate surgery. ${ }^{30}$

\section{Mucosal Defects}

For a long time, facial reconstruction following the tumor resection has been a difficult task. BFP has been successfully employed in the restoration of intraoral abnormalities, such as those caused by benign tumors and cysts. Post-operative radiation therapy should be considered when utilizing BFP to address faults caused by a malignant tumor. Any additional cancer treatment can result in bone exposure and a fistula. ${ }^{31,32}$ BFP should be saved for future use in malignant tumor patients as it can be used to treat bone necrosis defects. Excess fat may be necessary for restoration of tumor defects, and the patient's mouth opening may be limited. Loss of buccal fat can cause scar contracture and muscle adhesion because the buccal fat pad provides lubrication throughout numerous muscle contractions. For these patients, aggressive mouth opening exercise is recommended. Excessive grafting might lead to cheek depression. ${ }^{33,34}$

\section{Oral Submucous Fibrosis}

Oral submucous fibrosis is characterized by trismus, blanching, burning sensation in the mouth, rigidity of the oral mucosa, and hypomobility of the tongue and soft palate with loss of taste sensation. ${ }^{35}$ It's related to an increased juxtaepithelial inflammatory reaction, lamina propria appear fibroelastic followed by epithelial atrophy, resulting in oral mucosa stiffness and difficulty to chew. Various treatment options for oral submucous fibrosis have been investigated, but the buccal fat pad was shown to be the most effective because it provided good coverage without compromising the appearance. It was simple to execute, could be done as a day care operation with local anesthetic, and had low postoperative morbidity and good patient acceptance. ${ }^{36,37}$

\section{Temperomandibular Joint Reconstruction}

BFP has also been employed as an interpositioning material in the repair of the temporomandibular joint. The temporomandibular joint is reconstructed using free fat graft from the abdomen, resulting in improved function. ${ }^{38,39}$ After TMJ ankylosis release, Rattan employed BFP as an effective adjuvant to alloplastic or autogenous temporomandibular joint restoration. He concluded that because of the local availability of BFP and its adequate volume and long term fate it can be employed for TMJ reconstruction, but more research is needed to develop definitive conclusion. 40

\section{Osteoradionecrosis of the Jaw Bone}

Conservative treatment for osteoradionecrosis has been reported to have a success rate of 37-44 percent. Surgical intervention should be used for patients who cannot be managed with conservative therapy. Frequent dressing and additional antibiotics are the only non-surgical treatments for osteonecrosis. Hyperbaric oxygen therapy was also used in several trials due to the avascular nature of the condition. ${ }^{41}$ Surgical intervention involves removing all necrotic bone and reconstructing it with abundant vascularized tissue. For the recipient sites which have inadequately vascularized tissue beds, microvascular reconstruction has been employed for osteonecrosis reconstruction. ${ }^{42,43}$ The size and position of the osteonecrosis can occasionally make BFP repair difficult. Advanced stages of osteoradionecrosis have been observed to have worse reconstructive success rates than early stages. For advanced stages of osteoradionecrosis, a microvascular free flap can be employed. ${ }^{4}$

\section{Other Applications}

The BFP is used by Hassani et al. to cover the lateral wall of maxillary sinus and perform sinus augmentation with a mixture of natural bone mineral and autogenous bone. ${ }^{45}$ The upper lip frequently loses its normal curvature in patients who have maxillary advancement surgery with LeFort I osteotomy. BFP can be utilized as an augmentation substance to enhance the upper lip contour. ${ }^{46} \mathrm{BFP}$ can also be used to correct a skull base defect following tumor surgery. BFP can be employed to overcome Frey syndrome after parotid gland resection.

\section{Complications}

Recurrence of OAF and partial flap loss were two of the few problems linked with the buccal fat pad, which were predominantly encountered in large-sized defects. Whenever the buccal fat pad flap was used in the retromolar region, the most prevalent side effects were cheek distortions and mouth opening restrictions. Rarely haemorrhage and hematoma was observed due to one of the flap's pedicle, which was treated 
conservatively. Minimal obliteration of the vestibule, which will gradually resolve. ${ }^{10,47}$

\section{DISCUSSION}

To summariz due to its physical and biologic qualities, the buccal fat pad has been employed for a number of reasons in recent years, and the findings have encouraged doctors to take advantage of its potential benefits. The size of the defect appears to be the most important component in the BFP's success, While the literature claims that defects as large as 7 * $5 * 2 \mathrm{~cm}$ have healed successfully, most authors recommend 5 $* 4 \mathrm{~cm}$ (medium sized) defects for BFP repair. Bilateral flaps have been utilized if the deformities are substantial and near the midline, so that they can be dispersed across a large area. It has a wide range of applications, including closure of oroantral fistulas and the closure of post-excision maxillary abnormalities produced by benign and/or malignant tumors. ${ }^{16,48,31,8}$ It's been utilized for a variety of procedures, including closing of oroantral fistulas and closing of postexcision maxillary abnormalities produced by benign and/or malignant tumors. ${ }^{40}$

\section{CONCLUSIONS}

The BFP's effectiveness has been attributed to its low donor site morbidity, rich vascular supply, ease of harvesting, reliability as well as lower complication rate. ${ }^{28}$ Many uses have been developed since the introduction of BFP for maxillary repair. BFP provides number of advantages over other flap kinds. The surgical treatment is straightforward and has high rate of success. In variety of applications, BFP can be used to epithelialize without the need for a skin graft. When utilized in a poor vascularized recipient site, BFP's high vascularity is beneficial

Financial or other competing interests: None.

Disclosure forms provided by the authors are available with the full text of this article at jemds.com.

\section{REFERENCES}

[1] Gröbe A, Eichhorn W, Hanken H, et al. The use of buccal fat pad (BFP) as a pedicled graft in cleft palate surgery. Int J Oral Maxillofac Surg 2011;40(7):685-9.

[2] Salehi-Nik N, Rad MR, Kheiri L, et al. Buccal fat pad as a potential source of stem cells for bone regeneration: a literature review. Stem Cells Int 2017;2017:8354640.

[3] Soutar DS, Scheker LR, Tanner NS, et al. The radial forearm flap: a versatile method for intra-oral reconstruction. Br J Plast Surg 1983;36(1):1-8.

[4] Ashtiani AK, Fatemi MJ, Pooli AH, et al. Closure of palatal fistula with buccal fat pad flap. Int J Oral Maxillofac Surg 2011;40(3):250-4.

[5] Abdel-Aziz M, Fawaz M, Kamel M, et al. Closure of oroantral fistula with buccal fat pad flap and endoscopic drainage of the maxillary sinus. J Craniofac Surg 2018;29(8):2153-5.
[6] Marzano UG. Lorenz Heister's "molar gland". Plast Reconstr Surg 2005;115(5):1389-93.

[7] Baumann A, Ewers R. Application of the buccal fat pad in oral reconstruction. J Oral Maxillofac Surg 2000;58(4):389-92.

[8] Egyedi P. Utilization of the buccal fat pad for closure of oro - antral and / or oro - nasal communications. J Maxillofac Surg 1977;5(4):241-4.

[9] Neder A. Use of buccal fat pad for grafts. Oral Surgery, Oral Med Oral Pathol 1983;55(4):349-50.

[10] Tideman H, Bosanquet A, Scott J. Use of the buccal fat pad as a pedicled graft. J Oral Maxillofac Surg 1986;44(6):43540.

[11] Stuzin JM, Wagstrom L, Kawamoto HK, et al. The anatomy and clinical applications of the buccal pad of fat. Plast Reconstr Surg 1990;85(1):29-37.

[12] Yousuf S, Tubbs RS, Wartmann CT, et al. A review of the gross anatomy, functions, pathology and clinical uses of the buccal fat pad. Surg Radiol Anat 2010;32(5):427-36.

[13] Singh J, Prasad K, Lalitha RM, et al. Buccal pad of fat and its applications in oral and maxillofacial surgery: a review of published literature (February) 2004 to (July) 2009. Oral Surgery, Oral Med Oral Pathol Oral Radiol Endod 2010;110(6):698-705.

[14] Dubin B, Jackson IT, Halim A, et al. Anatomy of the buccal fat pad and its clinical significance. Plast Reconstr Surg 1989;83(2):257-64.

[15] Zhang HM, Yan YP, Qi KM, et al. Anatomical structure of the buccal fat pad and its clinical adaptations. Plast Reconstr Surg 2002;109(7):2509-20.

[16] Poeschl PW, Baumann A, Russmueller G, et al. Closure of oroantral communications with Bichat's buccal fat pad. J Oral Maxillofac Surg 2009;67(7):1460-6.

[17] Valencia LC, Pérez GF, Kaplan J, et al. Buccal fat pad excision: hydrodissection technique. Aesthetic Surg J 2019;39(10):1037-45.

[18] Jackson IT. Buccal fat pad removal. Aesthetic Surg J 2003;23(6):484-5.

[19] Abad-Gallegos M, Figueiredo R, Rodríguez-Baeza A, et al. Use of bichat's buccal fat pad for the sealing of orosinusal communications. A presentation of 8 cases. Med Oral Patol Oral Cir Bucal 2011;16(2):215-9.

[20] Hariram, Pal US, Mohammad S, et al. Buccal fat pad versus sandwich graft for treatment of oroantral defects: a comparison. Natl J Maxillofac Surg 2010;1(1):6-14.

[21] de Veras Filho RO, Giovanella F, Karsburg RM, et al. Oroantral communication closure using a pedicled buccal fat pad graft. Rev Odonto Ciência 2010;25(1):100-3.

[22] Nezafati S, Vafaii A, Ghojazadeh M. Comparison of pedicled buccal fat pad flap with buccal flap for closure of oro-antral communication. Int J Oral Maxillofac Surg 2012;41(5):624-8.

[23] Belmehdi A, El Harti K. Management of oroantral communication using buccal advanced flap. Pan Afr Med J 2019;34:69.

[24] Adeyemo WL, Ibikunle AA, James O, et al. Buccal fat pad: a useful adjunct flap in cleft palate repair. J Maxillofac Oral Surg 2019;18(1):40-5.

[25] Aziz SR, Rhee ST, Redai I. Cleft surgery in rural Bangladesh: reflections and experiences. J Oral Maxillofac Surg 2009;67(8):1581-8.

[26] Levi B, Kasten SJ, Buchman SR. Utilization of the buccal fat pad flap for congenital cleft palate repair. Plast Reconstr 
Surg 2009;123(3):1018-21.

[27] Tavakolinejad S, Bidskan AE, Ashraf H, et al. A glance at methods for cleft palate repair. Iran Red Crescent Med J 2014;16(9):e15393.

[28] Kim YK. The use of a pedicled buccal fat pad graft for bone coverage in primary palatorrhaphy: a case report. J Oral Maxillofac Surg 2001;59(12):1499-501.

[29] Musgrave RH, Bremner JC. Complications of cleft palate surgery. Plast Reconstr Surg Transplant Bull 1960;26:180-9.

[30] Jackson IT, Moreira-Gonzalez AA, Rogers A, et al. The buccal flap--a useful technique in cleft palate repair? Cleft Palate Craniofac J 2004;41(2):144-51.

[31] Hao SP. Reconstruction of oral defects with the pedicled buccal fat pad flap. Otolaryngol Head Neck Surg 2000;122(6):863-7.

[32] Sagayaraj A, Jyothi ND, Mohiyuddin SMA, et al. Role of buccal pad of fat in reconstruction of the buccal mucosa defects. Indian J Otolaryngol Head Neck Surg 2017;69(1):20-3.

[33] Zhong LP, Chen GF, Fan LJ, et al. Immediate reconstruction of maxilla with bone grafts supported by pedicled buccal fat pad graft. Oral Surg Oral Med Oral Pathol Oral Radiol Endod 2004;97(2):147-54.

[34] Choi HJ, Lee JB. Obliteration of recurrent large dentigerous cyst using bilateral buccal fat pad sling flaps. J Craniofac Surg 2016;27(5):e465-e8.

[35] Lambade P, Dawane P, Thorat A. Efficacy of buccal fat pad in the surgical management of oral submucous fibrosis: a prospective study. Oral Maxillofac Surg 2016;20(2):16770.

[36] Mehrotra D, Pradhan R, Gupta S. Retrospective comparison of surgical treatment modalities in 100 patients with oral submucous fibrosis. Oral Surg Oral Med Oral Pathol Oral Radiol Endod 2009;107(3):e1-e10.

[37] Sharma R, Thapliyal GK, Sinha R, et al. Use of buccal fat pad for treatment of oral submucous fibrosis. J Oral Maxillofac Surg 2012;70(1):228-32.
[38] Wolford M, Karras SC. Autologous fat tansplantation around temporomandibular joint total joint prostheses: preliminary treatment outcomes. J Oral Maxillofac Surg 1997;55(3):245-51.

[39] Bansal V, Bansal A, Mowar A, et al. Ultrasonography for the volumetric analysis of the buccal fat pad as an interposition material for the management of ankylosis of the temporomandibular joint in adolescent patients. $\mathrm{Br} \mathrm{J}$ Oral Maxillofac Surg 2015;53(9):820-5.

[40] Rattan V. A simple technique for use of buccal pad of fat in temporomandibular joint reconstruction. J Oral Maxillofac Surg 2006;64(9):1447-51.

[41] Wong JK, Wood RE, McLean M. Conservative management of osteoradionecrosis. Oral Surg Oral Med Oral Pathol Oral Radiol Endod 1997;84(1):16-21.

[42] Nabil S, Ramli R. The use of buccal fat pad flap in the treatment of osteoradionecrosis. Int J Oral Maxillofac Surg 2012;41(11):1422-6.

[43] Rotaru H, Kim MK, Kim SG, et al. Pedicled buccal fat pad flap as a reliable surgical strategy for the treatment of medication-related osteonecrosis of the jaw. J Oral Maxillofac Surg 2015;73(3):437-42.

[44] Chang DW, Oh HK, Robb GL, et al. Management of advanced mandibular osteoradionecrosis with free flap reconstruction. Head Neck 2001;23(10):830-5.

[45] Hassani A, Khojasteh A, Alikhasi M, et al. Measurement of volume changes of sinus floor augmentation covered with buccal fat pad: a case series study. Oral Surg, Oral Med Oral Pathol Oral Radiol Endod 2009;107(3):369-74.

[46] Rubio-Bueno P, Ardanza B, Piñas L, et al. Pedicled buccal fat pad flap for upper lip augmentation in orthognathic surgery patients. J Oral Maxillofac Surg 2013;71(4):e17884.

[47] Wolford DG, Stapleford RG, Forte RA, et al. Traumatic herniation of the buccal fat pad: report of case. J Am Dent Assoc 1981;103(4):593-4.

[48] Rapidis AD, Alexandridis CA, Eleftberiadis E, et al. The use of the buccal fat pad for reconstruction of oral defects. J Oral Maxillofac Surg 2000;58(2):158-63. 